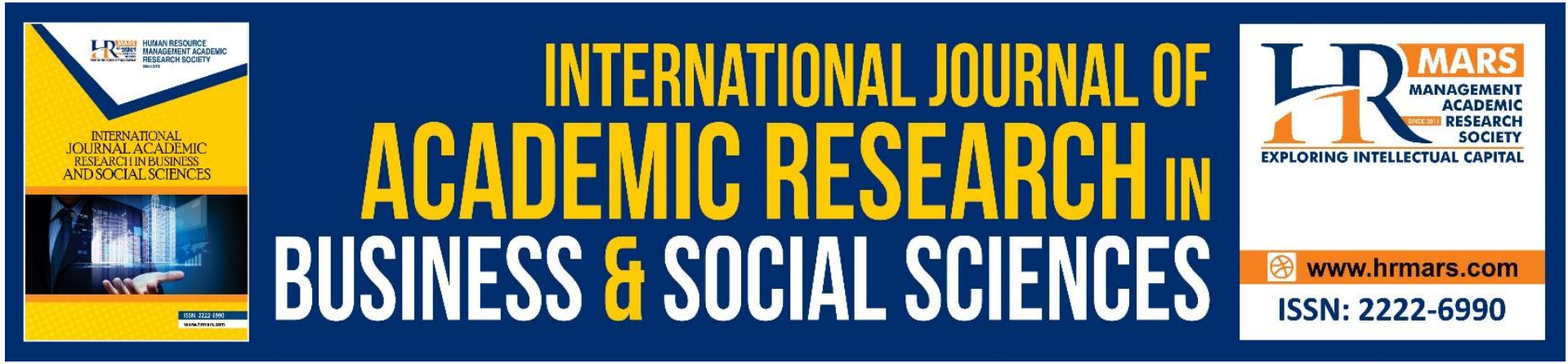

\title{
Language Learning Strategies Used by Year 4 Primary Pupils in Enhancing Reading Comprehension
}

Lim Shin Yee, Low Dee Hsia, Lydia Emak, Manoranjini Sandaraj, Sasirekha Kandasamy \& Harwati Hashim

To Link this Article: http://dx.doi.org/10.6007/IJARBSS/v11-i8/10164

DOI:10.6007/IJARBSS/v11-i8/10164

Received: 14 June 2021, Revised: 19 July 2021, Accepted: 02 August 2021

Published Online: 20 August 2021

In-Text Citation: (Yee et al., 2021)

To Cite this Article: Yee, L. S., Hsia, L. D., Emak, L., Sandaraj, M., Kandasamy, S., \& Hashim, H. (2021). Language Learning Strategies Used by Year 4 Primary Pupils in Enhancing Reading Comprehension. International Journal of Academic Research in Business and Social Sciences, 11(8), 787-798.

Copyright: @ 2021 The Author(s)

Published by Human Resource Management Academic Research Society (www.hrmars.com)

This article is published under the Creative Commons Attribution (CC BY 4.0) license. Anyone may reproduce, distribute, translate and create derivative works of this article (for both commercial and non-commercial purposes), subject to full attribution to the original publication and authors. The full terms of this license may be seen at: http://creativecommons.org/licences/by/4.0/legalcode

Vol. 11, No. 8, 2021, Pg. 787 - 798

Full Terms \& Conditions of access and use can be found at http://hrmars.com/index.php/pages/detail/publication-ethics 


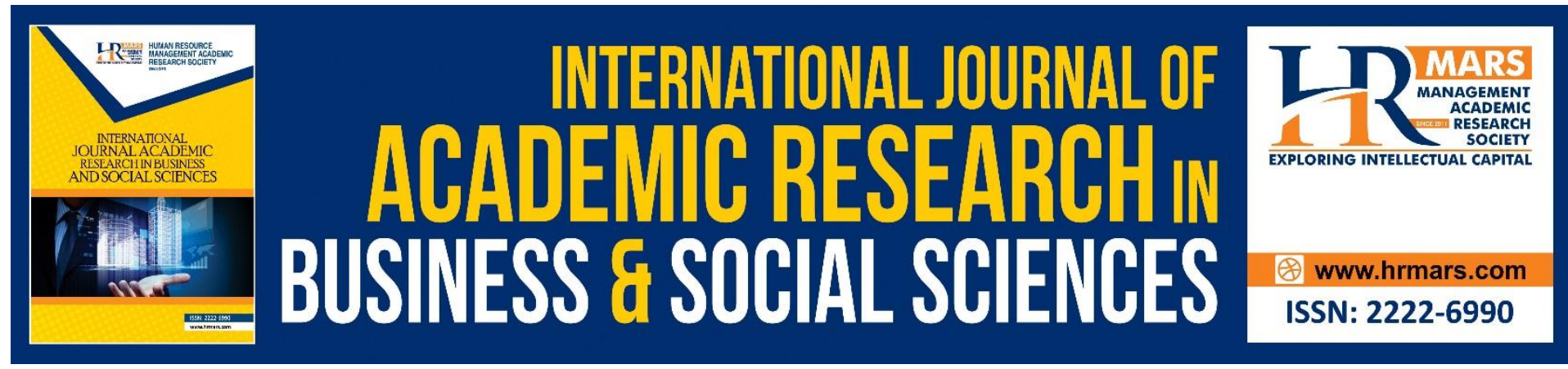

\title{
Language Learning Strategies Used by Year 4 Primary Pupils in Enhancing Reading Comprehension
}

\author{
Lim Shin Yee, Low Dee Hsia, Lydia Emak, Manoranjini \\ Sandaraj, Sasirekha Kandasamy \& Harwati Hashim \\ Faculty of Education, Universiti Kebangsaan Malaysia
}

\begin{abstract}
Reading comprehension is the ability to comprehend text, understand its meaning, and to connect with what the reader already knows. This study aims to investigate language learning strategies used by Year 4 primary pupils of a national-type Chinese secondary school in enhancing reading comprehension. Purposive sampling was used in this study where 15 males and 15 female pupils in Year 4 from a primary school in Selangor's suburbs were involved. This study employed a quantitative approach using survey adapted from 'Measuring ESL students reading strategies' by Kouider Mokhtari and Ravi Sheorey (2002) as instrument. The data from the survey was analysed using descriptive statistics and the most used learning strategies in reading comprehension was a Problem-Solving Strategies which the average score is 1.12 compared to other strategies; Global Reading strategies (1.0) and Support Reading Strategies (1.11). The findings revealed that the majority of the participants chose to apply ProblemSolving Strategies. Therefore, teachers should encourage and expose students the available language learning strategies and encourage them to use the strategies according to their required necessity and suitability. Future researchers should look into the characteristics that influence language learning strategies employed in reading comprehension by lower primary school students.
\end{abstract}

Keywords: ESL, Reading, Reading Strategies, Reading Comprehension, Language Learning Strategies.

\section{Introduction}

Over the years, there are countless studies and investigation done on Language Learning Strategy (LLS). The methods and actions taken by the learner to assist and aid them into the attainment of the language, storage and reclamation of information are defined as Learning Strategies. Strategies are defined as the learning methods, manners or activities, or learning-to-learn, problem-solving, or study skills. All these strategies contribute for a more competent and successful learning.

Language Learning Strategy (LLS) are identified as detailed practices or procedures used by individual students to expedite the understanding, memory, recovery and usage of knowledge for language learning and attainment (Oxford, 1990). In order to enhance the English skills, a student or a learner ought toward realize, learn, as well as generate the 
language learning strategies. Recognizing many forms of language learning strategies will provide the learner similar option in discovering approaches which are applicable to apply.

Fedderholt (2006: 1) contend that productive language learner deploy various forms of learning strategies. Undeniably, learning strategies surely contribute a remarkable influence on the result of language learning. Zainil (2005: 69) likewise state that currently, educators and researchers of English language consider in which the approaches compete a prime position in studying English since the student interest is not merely on mechanical appliances any longer but on evolving communicative expertise.

Teaching English as a second language should compete an incredibly critical position in order to facilitate the language beginner to develop the language proficiencies. Similar to other skills, in reading the beginners necessarily should understand the numerous styles of learning strategies despite require assistance from the educator in identifying and implementing the approaches. They require measures along with method to apply the approaches.

Evidently, the strategies will not be unable to carried out be properly if there is no solid effort contributed by the learner. In reality, a number of findings reveal that the students partaking constantly ascertain the achievement or the breakdown of the language learning. It could indicate the key principle of teaching English to support and assist the learner to learn autonomously through employing the types of learning strategies.

Language learning strategies may well occur in each stage. A learner commences to learn reading in English right the starting of elementary school, it implies that a learner starts to deploy learning approaches tutored by the educator. Repetition, imitation, memorization, using chart and games are standard learning strategies applied in this stage of education. It is fundamentally similar then the students be taught reading in higher level just in the same way as in a primary school, secondary and even in university.

Learning strategies comes in certain classifications. Cognitive, metacognitive and social learning strategies to name a few. O'Malley and Chamot (1990) clarify that student use metacognitive tools to help them focus, schedule, prepare, and track their progress in order to better organise their learning. This allows students to take control of their own education. In this way, it enables the students to prepare their learning strategies and adjust them if they are ineffective. Students may use cognitive techniques to assist them manage the target language or complete a task correctly. Reasoning, examination, and drawing conclusions are just to name a few. Drills can be used to learn the language, and dictionaries can deploy to look up complicated words. Socio-Affective learning strategies consist of collaborating with fellow student, acquaintances, educator discovering a native speaker to speak English.

Reading is an indispensable expertise in contemporary cultures which it is established through teaching and learning, as well as crucial toward studying in schools and beyond. Sloat et al. (2007) claim that students who fail to discover to read during primary level education may possibly unable to develop a capability to read properly in the next phase of education in the secondary or tertiary level. Consequently, students ought to seek a way towards developing a more sophisticated set of knowledge in reading early as these are seen as essential to grasp the procuring expertise, partaking in social and cultural life, being productive in a profession and partaking in lifetime knowledge gaining at all phases of existence (Grabe, 2009).

Additionally, it has remained contended where reading is the greatest substantial skill required by ESL students for intellectual accomplishment in English (e.g. Dabarera, et al., 2014; Ismail, 2015; Lee, 2012). This justify the necessity of English as a world language and 
gives impacts to its uses in most of the countries across the globe. This requirement formed the evolve of English as a medium of instruction in many education systems around the globe (Jensen, et al., 2013; Coleman, 2006). For instance, in Malaysia English has a leading role in language education policies, since governments and other communal services such as schools, educators and parents deem that competence in English is the core of educational success (Baldauf et al., 2011).

These contentions indicates that reading in English is crucial in Malaysia where English is a second language (ESL), and it is employed as a medium of instruction in all fields. Due to to the significance value of reading in English, there is a great drive to enhance the number of proficient English language readers. Hence, the aim of this research was to explore into language learning strategies used by Year Four primary school pupils of a national-type Chinese primary school (pls check if this term is correct to replace SJKC) in reading comprehension.

\section{Literature Review \\ Reading}

Reading can be described as perceiving words, including their spelling and relationships to other words in a sentence, in extremely basic terms. Overall, it's a method of extracting and constructing meaning from a given material within a composed structure (Aukerman, 2013). Reading in a second language is a difficult skill to master, and it is often regarded as the most long-lasting second language learning skill (Bernhardt, 1993). To put it another way, "reading is the practise of deriving meaning from written symbols by combining cognitive and psychomotor skills" (Demirel, 2016).

\section{Defining Reading Comprehension}

Reading has been researched and analysed from a variety of perspectives for several years. Reading has been identified as a valuable source of information by a number of researchers. Reading is also an input that is essential for learning a new language. As students read and comprehend a text, they are able to merge the text's details with their background knowledge. The reader, on the other hand, is traditionally conceived as a passive figure who only receives knowledge and must interpret the context contained within the text. The capacity of the mind to interpret and comprehend concepts is known as comprehension. It refers to a complex mental process that allows you to understand and remember important details in a text. As a result, the reader should deduce information from the text that is mentioned explicitly or implicitly in order to comprehend its meaning.

Comprehension is described by (Alfassi, 2004; Meneghetti, Carretti, \& De Beni, 2006) as the connection between the text being read and the reader's prior knowledge and expectations, which generates meaning and comprehension. This means that comprehension is an internal process that should be triggered by some external events that allow our readers to achieve higher levels of reading comprehension. Understanding is a process rather than a product. The text and the reader have a constructive relationship in which the latter evaluates the text. The reader will be able to comprehend the text as a result of this interaction. As a result, the reader is captivated by the author's meaning, and this interaction generates a combination of feelings and emotions that are based on real-life experiences. 
Reading comprehension is dependent on the reader's ability to connect with the content. According to Pearson et al (1992), a better reader employs the following skills and tactics.: (1) make sense of new information using prior knowledge, (2) Before, during, and after reading, ask questions regarding their material; (3) infer from the text; check understanding (4) use strategies to get (5) identify main ideas and (6) determine what matters; and combine data to produce a sensory image. "The achievement of reading comprehension is dependent on variables such as types of text, the class of content structure, the reader's language skill, content complexity, and task requirements," according to Alderson (2000).

Reading comprehension, according to Mckee (2012), is characterised as the ability to comprehend texts, analyse the information contained in the texts, and correctly interpret the writer's statements and intentions. Reading comprehension, on the other hand, is described by Hans \& Hans (2015) as a person's ability to comprehend a text. This form of comprehension is based on how written words generate knowledge that exists outside of the text. To put it another way, comprehension in this context is a dynamic but imaginative process that is dependent on the four language skills (phonology, pragmatics, semantics, and syntax). Furthermore, according to Bulut (2017), reading comprehension is one of the most important language skills since it entails making meanings and recognising information in written texts, whether they are explicit or not.

\section{Reading Comprehension Strategies}

Learning strategies are significant aspects that influence the learning process and outcomes, as well as specific actions students take to improve their learning performance. (Shi, p. 20, 2011). Language learning strategies are divided into six categories, according to Oxford (2003, p. 2): memory, cognitive, compensatory, metacognitive, affective, and social strategies. It is critical to instil in students the belief that reading, especially reading with comprehension, is critical not only in school but also in everyday life. Whether it's for the purpose of learning something new, expanding one's knowledge, or searching for information, the ability to read with comprehension is needed (Maagero \& Seip Tonnessen, 2006).

Reading strategies describe how readers handle their interactions with text in order to achieve successful L2 reading comprehension. (Anastasiou \& Griva, 2009). The reader, the text, the tactics, and the objective are all key variables in the reading comprehension process, according to Lipka and Siegel (2012). Reading techniques are of particular relevance among the four elements since they are a crucial component in the development of L2 reading comprehension (Kücükolu, 2013).

According to Block (1986), the use of techniques improves students' reading comprehension because they show how students make sense of what they are reading and how they perceive and resolve misunderstandings while performing a particular assignment. Reading techniques, according to Barnett (1989:66), are "the mental operations involved when readers deliberately approach a text in order to make sense of what they read." Then, each technique must be carefully described, as well as the most appropriate way to implement it in each reading stage. 
Paying attention to reading, adjusting reading rate, reading slowly, visualising content, reading material aloud, and guessing the meaning of unknown words are all mentioned by Mokhtari and Reichard (2002) as three beneficial categories of such tactics. Support Reading entails summarising text content, taking notes while reading, asking oneself questions, sharing one's reading with others, using reference books as aids, and reviewing previously read material; and Global Reading entails enabling prior knowledge, creating text forecasts, skimming text, exploiting background hints, and utilising text structure and textual aspects.

\section{Global Reading Strategies}

Global Reading Strategies are a collection of common reading strategies that we use while we learn. Many of these approaches include focusing on what we're reading and why we're reading it, and many of them just include the text at hand. Global Reading Strategies can be used with any sort of reading, and they usually include building a relationship with the text and focusing on what you've read. The following are some examples of global reading strategies:

- Creating a reading target to keep in mind

- Thinking about what you learned to help you understand the reading

- Relating the text to your reading intent when reading

- Using charts, statistics, and pictures to make you understand the reading

- Paying careful attention to bolded or italicised things

\section{Problem-Solving Strategies}

Problem-Solving Strategies are precisely that: tools for addressing problems while reading. What do you do when the material becomes noticeably harder to comprehend? What do you do if you come across a word you're unfamiliar with? What do you do if you've read the first two or three pages of a chapter but have no idea what you've read? In both of these situations, you'll need to solve the problem in order to read and comprehend the text effectively. Among the Problem-Solving Techniques are:

$>$ To deal with difficult content, read slowly and change your reading pace.

$>$ When you get off track, re-reading will help you get back on track.

$>$ When a text becomes difficult, pay careful attention and reread it.

$>$ Taking a few moments to reflect on what you've read

- Using pictures or visualisations to help people remember what they've learned.

\section{Support Reading Strategies}

Support Reading Techniques are also straightforward: they are methods for providing assistance to readers in order to increase comprehension and retention. How do you make sure you know what you've read after you've laid your textbook down? How do you link the ideas in the textbook to the larger picture, such as what you're studying in class or doing in the lab or with patients? Support Reading Strategies will help you make connections and put what you've learned into practise. Some Reading Support Strategies include:

$>$ Taking notes as you learn to help you understand what you're reading and make broader connections

$>$ Summarizing what you've read in order to draw on key points and facts 
$>$ Discussing what you've read with others to help you make connections and gain a better understanding

$>$ Using reference materials to classify words or concepts that you don't grasp at first

$>$ Using your reading to ask yourself questions that you'd like addressed

It is important to have a clear understanding of what a technique is in order to identify the most appropriate reading strategies for improving reading comprehension. As a result, a strategy is described as a well-thought-out plan or method for achieving a specific objective over a long period of time. This means that understanding the intent of reading a text is critical in determining the best method for achieving it.

\section{Related Past Studies on Language Learning Strategies used in Reading Comprehension}

Reading and learning techniques are inextricably linked, and what is essential in learning processes can also be applied to reading comprehension (Roe, 2014:84). When conducting tasks and processing new input, the students employ a variety of language learning techniques. Reading comprehension is a two-way mechanism in which the reader and the text communicate. Using his or her prior experience and successful reading comprehension techniques, the reader derives meaning from the text throughout the reading process (Orasanu \& Penny, 1986).

Given the results of most language learners' language learning strategies in reading comprehension and the effects of using language learning strategies on reading comprehension, it can be concluded that cognitive strategy is more commonly used by language learners than metacognitive and social strategies (Muhammad, 2015).

Given that learners' attitudes toward language learning are significantly correlated with their reading comprehension achievement and vocabulary understanding, it can be concluded that students' attitudes toward language learning play a role in their reading comprehension capacity, especially in the skill of making sense of English words (Riyanto, 2015)

In attempt to uncover successful reading approaches that can aid increase Reading Comprehension, several researches have compared technique utilisation between more and less involved readers (Zhang et al., 2008; Anastasiou \& Griva, 2009; Mokhtari, 2008); For instance, a study of 201 sixth-grade Greek-speaking primary school pupils aged 11 to 12 years old looked at how they used reading methods in English literature. Past interviews and reading test data were used in the study. Both groups used a range of cognitive techniques, according to the findings, weak readers were less aware of the great degree of intellectual strategies than strong readers.

Other researches have looked at the use of various reading techniques including metacognitive and cognitive strategies to improve reading comprehension (Wang, 2015; Zare, 2007). Several research at the secondary and tertiary levels looked into reading techniques used in various texts, activities, and environments (Cogmen \& Saracaloglu, 2009). Malcolm (2009), For instance, at a medical university in Bahrain, a questionnaire was utilised to test the reading comprehension strategies among $160 \mathrm{EFL}$ students. The study discovered that all students used metacognitive techniques frequently in general, as well as basic strategies for 
translating from English to Arabic. Students with poor basic English ability and those in their first year noted utilising interpretation more when reading English medical texts. Fourth-year students used less translations and more metacognitive methods. This indicates that reading strategies are critical not only for improving comprehension in English texts, but also in other academic texts.

The approaches used by primary school students have been the subject of many studies. Identifying reading techniques that can help enhance reading comprehension (e.g. Alsheikh \& Haq, 2011). Researchers investigated how specific reading approaches, such as metacognitive and cognitive strategies, can aid in the improvement of reading comprehension. (e.g., Anjomshoaa et al., 2012; Hosseini et al.).

\section{Methodology \\ Participants}

This study employed a quantitative approach using survey as method. The targeted participants were consisted of 15 male and 15 female Year 4 pupils from a national-type Chinese primary school in suburban Selangor. The participants are from mixed ability background and were chosen utilizing purposive sampling method

\section{Instruments}

A questionnaire was utilised as an instrument of data collection. Questionnaires are very commonly used in exploring language learning strategies involving different types of behaviour questionnaires and strategy dealing with factor analysis. In this study, the reading strategy survey was based on the Metacognitive Reading Awareness Strategy Inventory (MARSI), which was originally written by Kouder Mokhtari and Ravi Sheorey in 2002. It is a 30item Likert-type questionnaire with five responses, the objective of which is to determine the various reading strategies of students when reading academic materials in English. Each statement is given in the form of a 5-point Likert scale, ranging from 1 (I never or almost never do this) to 5 (I always or almost always do). However, the instrument was amended to a form of 2- point Likert scale collecting on only YES or NO responses due to the fact that the Year 4 children at the ages of 10 are not fully developed cognitively and metacognitively.

\section{Data Collection Procedure and Analysis}

The survey was administered to the participants and they were given 30 minutes to complete the survey. The data from the survey was analysed using descriptive statistics to determine of most and least used of the learning strategies in reading comprehension based on frequencies of YES and NO for each question and the overall average scores that indicates how frequently the participants use reading strategies when reading academic materials.

\section{Findings and Discussions}

Indications that there are classifications of LLS into cognitive, meta-cognitive, and social types of strategies. This survey of reading strategies have categorized them into three main parts, which includes global reading strategies, problem solving strategies and support reading strategies. The data analysis of the study results is presented in two parts. The first part is the presentation of the means and standard deviations for the three categories and overall reading strategies. The second part is the presentation of the five most used and the five least used strategy items. 
The Mean for each of the three categorised strategies as well as the overall reading strategy are presented in Table 1.1

\begin{tabular}{lccc}
\hline Category & Mean & SD & Rank \\
\hline Global Reading Strategies & 3.55 & 0.50 & 2 \\
Problem-Solving Strategies & 4.04 & 0.50 & 1 \\
Support Reading Strategies & 3.52 & 0.58 & 3 \\
Overall Reading Strategies & 3.67 & 0.45 & --
\end{tabular}

Table 1.1 Means and Standard Deviations for the three categories and overall strategies

According to Table 1.1, problem-solving strategies (PROB) are the most popular, followed by global (GLOB) and support strategies (SUP). This is in line with several studies that looked at people's opinions of reading strategies via SORS. In general, participants' inclined towards problem-solving strategies indicates that readers have awareness towards their reading process and thereby possess the capability of taking actions while reading so as to overcome their reading difficulties.

Analysis of the collected data from the selected population are represented by Chart 3.1, Chart 3.2, and Chart 3.3.

\section{GLOBAL Reading Strategy}

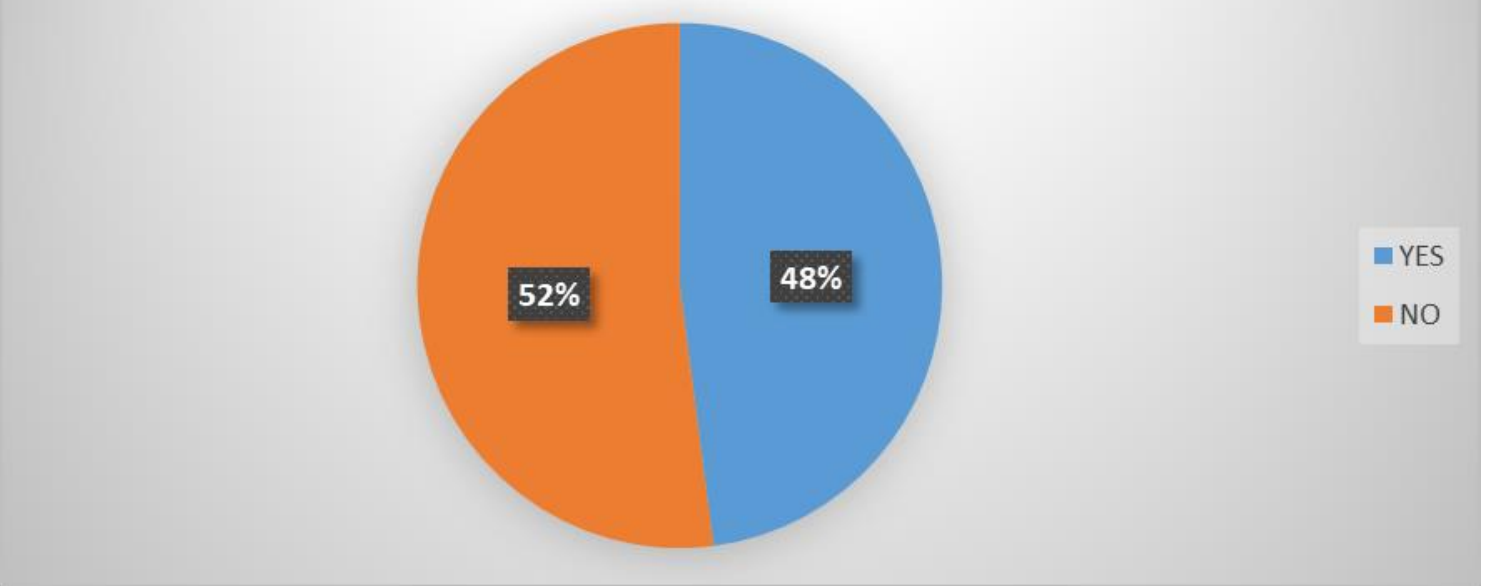

Chart 3.1. Percentage Analysis of Global Reading Strategy

According to Chart 3.1, there are $48 \%$ of the respondents choose 'Yes' and $52 \%$ choose 'No' from the overall 13 GLOB items. Item such as "I check to see if my guesses about the text are right or wrong" (Item 27, GLOB), are the most preferable item among GLOB as it display the students' degree of reading awareness of their reading comprehension process and the strategies they devoted to solve whichever reading problems, which could indicate that students, especially second language learners will always double confirm if they are not familiar with the text that are difficult for them. Furthermore, the students" reported "I have a purpose in mind when I read" (Item 1, GLOB) was the second most popular global reading strategy, suggesting that participants planned ahead of time before reading. It demonstrates that kids have a strategy and a clear perspective when reading. 


\section{PROBLEM-SOLVING Reading Strategy}

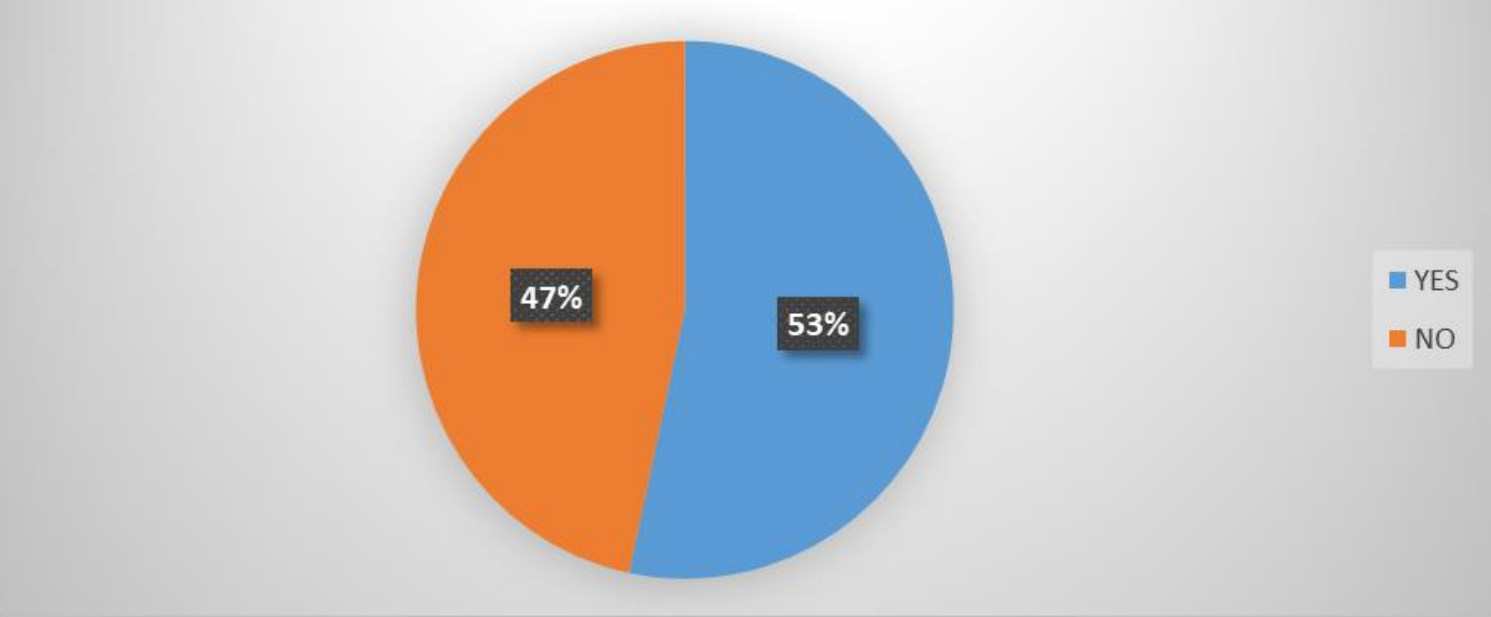

Chart 3.2. Percentage Analysis of Problem-Solving Reading Strategy

According to Chart 3.2, there are 53\% of the respondents choose 'Yes' and $47 \%$ choose 'No'. The most favorite item in this strategy was "I read slowly and carefully to make sure I understand what I am reading" (Item 7, PROB), which indicates the students' positive reaction to put more attention to ensure the reading material can be deeply understand. Next favourable item is "When text becomes difficult, I re-read it to increase my understanding" (Item 25, PROB), which presents the students' enthusiastic action to read when comprehension is difficult to understand. And also "When text becomes difficult, I pay closer attention to what I am reading (Item 14, PROB). It has been proven that problem-solving strategy practise goes hand in hand with proficient reading, and that competent readers use these methods to increase and manage their reading comprehension.

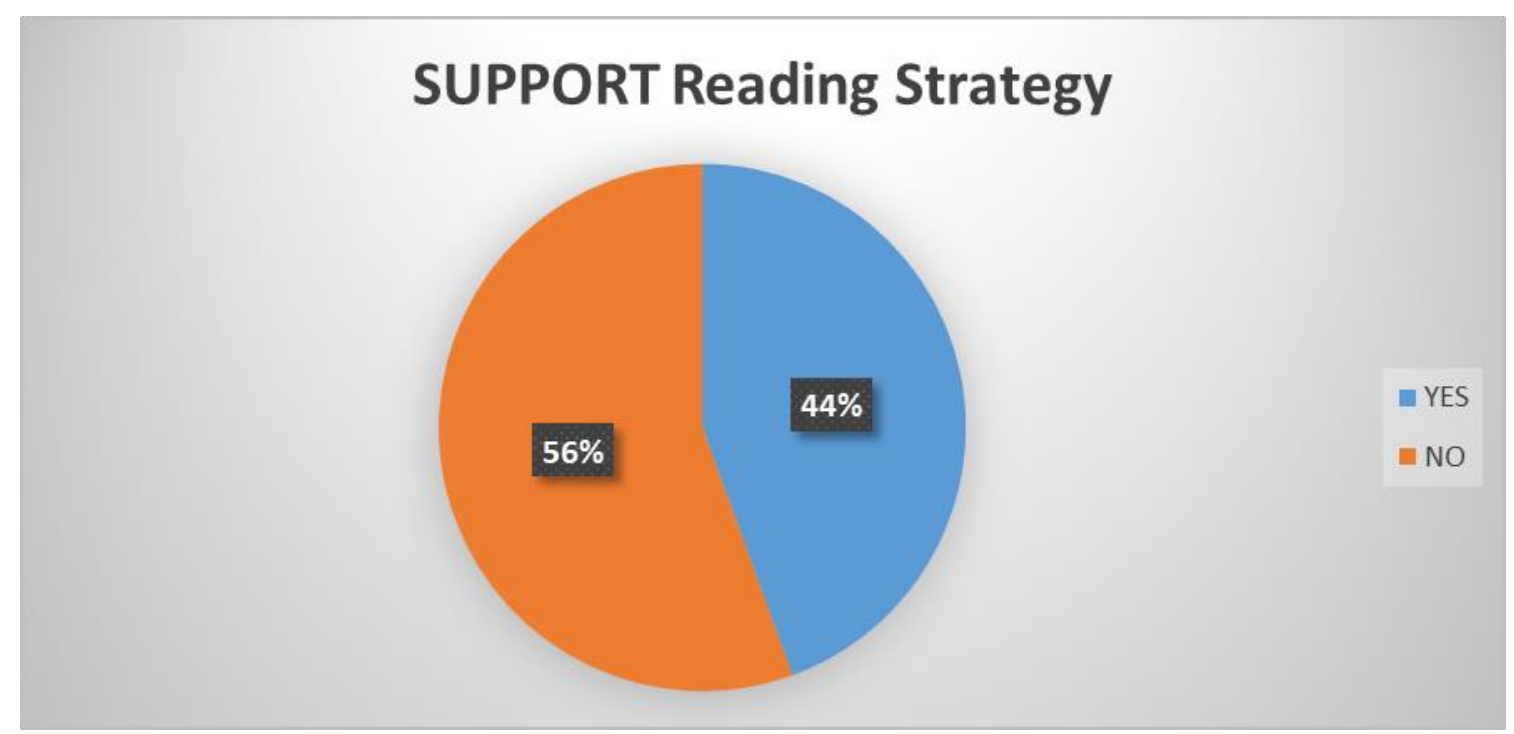

Chart 3.3. Percentage Analysis of Support Reading Strategy

According to Chart 3.3, there are $44 \%$ of the respondents choose 'Yes' and $56 \%$ choose 'No' for support reading strategy. According to the survey results, the SUP strategy was the least used sub-category. Strategies such as "When reading, I translate from English into my native language" (Item 29, SUP), "When reading, I think about information in both English and 
my mother tongue" (Item 30, SUP), and "I use tables, figures and pictures in text to increase my understanding" (Item 15) were the least preferred. Because the efficacy of support strategies is highly dependent on the context in which they are used, this finding could imply that the participants' flexibility in strategy use, as well as their autonomy in selecting methods that best suit their requirements.

\section{Implications and Conclusions}

The study provides an insight to language teachers on some of the strategies applied by the pupils in SJKC primary school particularly in learning English reading skill. LessardClouston, 1997 suggested that a teacher should always plan their lesson focusing on the needs of the students, the types of task planned for the day, and also review their own teaching. Besides that, a teacher also should also assess their students' interests, motivations, learning styles by observing them in classroom. All this could be conducted either formally or informally in class by the teacher teaching the lesson.

The materials used in class should be within the level of the students and of their interest. Lessard-Clouston, 1997, also suggested teachers who review their students, their tasks assigned, and also their own method of teaching will be better at producing lessons that would focus on language learning strategies which will suit best to the students need. It is equally important to apply differentiated learning in the classroom. Teacher must prepare a lesson that cater to the learning level of each group student. One mould does not fit all, thus careful planning is required before each lesson to ensure everyone achieves the lesson objectives at their own pace.

Teachers should encourage and expose students the available language learning strategies and encourage them to use the strategies according to their required necessity and suitability. Teachers also should encourage students to keep record or journal of the various strategies that they applied and that have worked best for them. Teachers also should provide the suitable learning context, thus giving the students the room to test out and apply the learning strategies so they can identify the best learning strategy that help them achieve their desired short term and long-term goal. This would guarantee that the students are conscious of the availability of different learning strategies.

In conclusion. the opportunity to practice the various learning strategy will ensure students improve language skill particularly the reading aspect. It is hoped that the findings of this research will be useful to researchers who want to have a finer mastery of this topic. It is recommended for future researcher to study on factors which influence language learning strategies use by the lower primary school pupils.

\section{References}

Alfassi, M. (2004). Reading to learn: effects of combined strategy instruction on high school students. The Journal of Educational Research, 97(4), 171-184.

Anastasiou, D., \& Griva, E. (2009). Awareness of reading strategy use and reading comprehension among poor and good readers. Ilkögretim-Online, 8(2), 283-297.

Aukerman, M. (2013). Rereading comprehension pedagogies: Toward a dialogic teaching ethic that honors student sensemaking. Dialogic Pedagogy, 1, 1-31. https://doi.org/ 10.5195/dpj.2013.9

Barnett, M. A. (1988). Teaching reading in a foreign language. ERIC Digest Clearinghouse on Languages and Linguistics Washington DC Barnett, 
Block, D. (2003). The Social Turn in Second Language Acquisition'. Edinburgh University Press Ltd.

Bialystok, E. (1985). The compatibility of teaching and learning strategies. Applied Linguistics; 6/3, 255-262.

Bernhardt, E. B. (1993). Reading Development in A Second Language: Theoretical, Empirical, \& Classroom Perspectives. London: Ablex Publishing Corporation.

Bernhardt, E. B. (2011). Understanding Advanced Second-Language Reading. New York: Routledge Taylor and Francis Group.

Bialystok, E. (1981). The role of conscious strategies in second language proficiency. Modern Language Journal, 65, 24-35.

Carrell, P. L., \& Carson, J. G. (1997). Extensive and intensive reading in an EAP setting. English for Specific Purposes, 16, 47-60. https://doi.org/10.1016/S0889-4906(96)00031-2

Embi, M. A. (2000). Language learning strategies: A Malaysian context. Bangi, MYS: Faculty of Education.

Krashen, S. D. (1982). Principles and practice in second language acquisition. Oxford: Pergamon. Lotfiyan Moghaddam, Mehdi (2003).»The relationship between reflection through keeping language learning diaries by Iranian EFL learners, Their language learning strategies and language proficiency level». Unpublished M.A Thesis, Tarbiat Modarres University, Tehran.

Krashen, S. D. (1985). The Input Hypothesis: Issues and Implications. New York: Longman

Lessard-Clouston, M. (1997). Language learning strategies: An overview for L2 teachers. The Internet TESL Journal, 3 (12)

Lipka, O., \& Siegel, L. S. (2012). The development of reading comprehension skills in children learning English as a second language. Reading and Writing, 25(8), 1873-1898.

Maarof, N., \& Yaacob, R. (2011). Meaning-making in the first and second language: Reading strategies of Malaysian students. Procedia - Social and Behavioural Sciences, 12, 211223.

Mokhtari, K., \& Reichard, C. (2002). Assessing students' metacognitive awareness of reading strategies. Journal of Educational Psychology, 94, 249-259.

Orasanu J, And Penny, M. (1986). Introduction comprehension theory and how it grew. Reading comprehension; from research to practice, (pp) 1-10.

Oxford, R. L. \& Ehrman, M. (1995). Adults' language learning strategies in an intensive foreign language program in the United States. System, 23(3), 359-386.

Richards, J. C., \& Schmidt, R. (2002). Longman Dictionary of Language Teaching and Applied Linguistics. Malaysia: Pearson Education.

Vann, R. J., and Abraham, R. G. (1990). Strategies of unsuccessful language learners. TESOL Quarterly; 24/2, 177-198.

Mokhtari, K., \& Sheorey, R. (2002). Measuring ESL students reading strategies. Journal of Developmental Education, 25 (3), pp. 2-10. 